\title{
Retrospective analysis of urine culture results in our clinic: determination of pathogen types and antibiotic resistance in our region
}

\author{
๑Mustafa Tekin ${ }^{1}$, @Navdar Doğuş Uzun ${ }^{1} \oplus$ Fulya Uzun ${ }^{1} \odot$ Erkan Sanmak $^{2}$ \\ ${ }^{1}$ Mardin State Hospital Obstetrics and Gynecology Department, Mardin, Turkey \\ ${ }^{2}$ Mardin State Hospital Microbiology Department, Mardin, Turkey
}

Cite this article as: Tekin M, Uzun ND, Uzun F, Sanmak E. Retrospective analysis of urine culture results in our clinic: determination of pathogen types and antibiotic resistance in our region. J Health Sci Med 2021; 4(1): 28-32.

\begin{abstract}
Aim: Untreated urinary tract infections and increasing resistance to antibiotics are important health problems in pregnant and non-pregnant women. The aim of this study is to determine "Escherichia coli" (E. Coli) strains and other growing microorganisms isolated from urine samples sent from pregnant and non-pregnant patients in the Gynecology and Obstetrics outpatient clinic in Mardin State Hospital, and evaluate the antimicrobial susceptibility profile.

Material and Method: The results of reproduction in midstream urine samples obtained from pregnant and non-pregnant women who were sent to Mardin State Hospital Microbiology Laboratory with the suspicion of urinary system infection from the Gynecology and Obstetrics Outpatient Clinic between January 1, 2018 and June 17, 2020 were retrospectively evaluated.

Results: The mean age of pregnant patients was significantly lower than that of the non-pregnant group. While E. Coli and Klebsiella were prominent in the pregnant group, the incidence of E. Coli and Enterococcus spp. had increased in the nonpregnant group.

Conclusion: Urinary tract infection remains an important public health problem. To prevent the adverse obstetric consequences of urinary tract infection during pregnancy, it is important to investigate local susceptibility of microorganisms, especially common factors such as E. Coli, at certain periods.
\end{abstract}

Keywords: Urinary tract infection, pregnancy, Escherichia coli, antibiotic sensitivity, bacteriuria

\section{INTRODUCTION}

Symbiotic bacterial cells found in the skin, mucosa, intestine and oral cavity in humans constitute the human microbiota. Microbiota protect tissues from pathogenic microorganisms by increasing mucosal barrier resistance. During pregnancy, changes occur in the female body, especially in the vaginal microbium. Changes in vaginal acidity are also one of the important reasons for the increase in the frequency of urinary tract infections during pregnancy.

All bacterial infections considered, while urinary system infections are the most common, the most frequently isolated microorganism in laboratories is "Escherichia coli" (E. Coli). Urinary infection occurs when microorganisms move retrogradely towards the bladder through the urethra. E. Coli, the most common agent in urinary system infections, is a member of Enterobactericeae, and found in the intestinal flora $(1,2)$. Extended spectrum beta-lactamase (ESBL) production is one of the principal resistance mechanisms developed by Enterobactericeae members (3). In addition to the typical clinical symptoms, the diagnosis is made by showing the reproduction of the pathogen in urine culture (4). The presence of pyuria, hematuria, or bacteria in the microscopy of the urine is the main data suggesting urinary tract infection. However, the visualization of leukocyte casts suggests pyelonephritis. The presence of abundant squamous cells indicates that the urine sample is contaminated, and the culture result may be misleading.

Urinary tract infection in non-pregnant women is usually a self-limiting condition if there is no secondary disease such as diabetes mellitus, conditions that cause immunosuppression, ureter stone, or renal failure. Urinary 
tract infection in pregnant women can lead to complications with serious morbidity and mortality, such as preterm labor, pyelonephritis, premature rupture of membrane, and chorioamnionitis. Although urinary tract infection during pregnancy is usually asymptomatic, pathogenic microorganisms can grow more conveniently with the decrease of ureter peristalsis due to progesterone, decrease in the bladder capacity with the compression of the uterus on the bladder, and the change of vaginal flora, which is the reason urinary tract infection can rapidly progress to acute pyelonephritis (5). The American College of Obstetricians and Gynecologists (ACOG) reports that pregnant women should be given appropriate treatment for urinary tract infections, or serious maternal and fetal complications may occur (6).

An increasing resistance is observed against antibiotics used in empirical treatment in symptomatic patients (7). The widespread use of antibiotics in our country, the patients' compliance problem and the use of advanced generation antibiotics as the first choice in treatment are the primary causes of resistance development. In the European Association of Urology (EAU) manual, it is stated that if a resistance exceeding $20 \%$ is detected against an antibiotic used in urinary tract infection, that drug should not be used in empirical treatment (8).

The aim of this study is to determine E. Coli strains and other bacteria isolated from urine samples obtained in the outpatient clinics in our hospital, their antimicrobial susceptibility profile, and investigate their resistance against antibiotics commonly used in empirical treatment in clinical practice.

\section{MATERIAL AND METHOD}

A total of 158 samples with growth in midstream urine samples obtained from pregnant and non-pregnant women who were sent to Mardin State Hospital Microbiology Laboratory with the suspicion of urinary tract infection from the Gynecology and Obstetrics Outpatient Clinic between 1 January 2018 and 17 June 2020 were retrospectively investigated. Ethics approval was obtained from Mardin Provincial Directorate of Health's Ethics Committee (Document no: 37201737-806.02.021332, Date: $27 / 08 / 2020)$ and the research was carried out in accordance with the Helsinki Declaration, published by the World Medical Association. Urine samples were inoculated on Eosin Methylene Blue (EMB) and 5\% sheep blood agars. Microorganisms grown after 24 hours of incubation were conventionally pre-defined. After that Gram staining method was performed. According to Gram staining properties, chemical properties were determined by tests such as catalase, sugar fermentation, citrate use, indole test, urea test, oxidase test, PYR test. After the pre-identification, the automated system VITEK $2^{\circledast}$ (Biomerieux, France) was identified. Conventional methods and VITEK $2^{\circledast}$ (Biomerieux, France) automated bacterial identification system were used for identification of isolated microorganisms. VITEK $2^{\circledR}$ (Biomerieux, France) automated susceptibility system was used for antibiotic susceptibility tests, which were performed in accordance with the recommendations of CLSI (Clinical and Laboratory Standards Institute) and EUCAST (European Committee on Antimicrobial Susceptibility Testing). CLSI criteria and recommendations were used only for the first six months of 2018. Among the materials available by the current laboratory, in accordance with the CLSI recommendations, MHA and 5\% sheep blood agars were used for rare bacteria, and not the $\mathrm{MH}-\mathrm{F}$ agar, which was recommended by the EUCAST. The CLSI criteria were used for the minimum inhibitory concentration of nitrofurantoin for enterococci other than Enterococcus faecium, as that was not available in the EUCAST.

Based on the studies of Belete et al. (9) (2020), the minimum number of patients for each group was 45 , with 95\% confidence interval and 1.6448536 effect size.

\section{Statistical Methods}

Nominal and ordinal data were described with frequency analysis, and scale parameters were described by mean and standard deviations. Chi-Square Test and Chi-Square Likelihood ratio were used for differences between categorical parameters. Kolmogorov Smirnov test was used for normality of age. Mann Whitney $U$ test was used for age difference, since the distribution was non-nornal. SPSS 17.0 for windows was used with 95\% Confidence Interval.

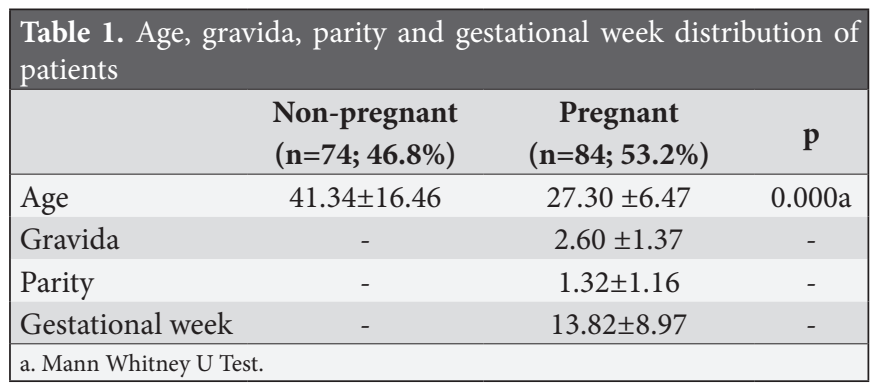

\section{RESULTS}

Age, gravida, parity and gestational week distribution of patients were given in the Table $\mathbf{1}$.

Seventy-four non-pregnant and 84 pregnant women were subjected to the study. Age mean of non-pregnant group was statistically higher than age mean of pregnant group $(\mathrm{p}<0.05)$. Gravida mean of pregnant patients was $2.60 \pm 1.37$, parity mean was $1.32 \pm 1.16$, and gestational week mean was $13.82 \pm 8.97$.

Microorganism distribution based on groups was given in the Table 2. 


\begin{tabular}{|lccc|}
\hline \multicolumn{4}{l}{ Table 2. Microorganism distribution based on groups } \\
& $\begin{array}{c}\text { Non-pregnant } \\
(\mathbf{n}=\mathbf{7 4} ; \mathbf{4 6 . 8} \%)\end{array}$ & $\begin{array}{c}\text { Pregnant } \\
(\mathbf{n}=\mathbf{8 4} ; \mathbf{5 3 . 2} \%)\end{array}$ & $\begin{array}{c}\text { Total } \\
(\mathbf{n}=\mathbf{1 5 8})\end{array}$ \\
\hline $\begin{array}{l}\text { E. Coli } \\
\text { Staphylococcus saprophyticus }\end{array}$ & $24(59.5)$ & $51(60.7)$ & $95(60.1)$ \\
Staphylococcus epidermidis & $2(2.7)$ & $1(1.2)$ & $3(1.9)$ \\
Streptococcus agalactiae & $4(5.4)$ & - & $2(1.3)$ \\
Klebsiella pneumoniae & $5(6.8)$ & $11(13.1)$ & $7(4.4)$ \\
Staphylococcus aureus & $4(5.4)$ & $2(2.4)$ & $6(3.8)$ \\
Enterococcus sp. & $5(6.8)$ & $1(1.2)$ & $6(3.8)$ \\
Enterobactericeae Spp. & $1(1.4)$ & $1(1.2)$ & $2(1.3)$ \\
Coagulase (-) negative & $3(4.1)$ & $4(4.8)$ & $7(4.4)$ \\
staphylococcus & & & \\
Other & $4(5.4)$ & $10(11.9)$ & $14(8.9)$ \\
\hline p=0.223>0.05 & & \\
\hline
\end{tabular}

In both patient groups, E. Coli was the most common species among other microorganisms, followed by Klebsiella pneumoniae. Enterococcus spp. was higher in the non pregnant group. Difference analysis results showed that differences between patient groups were insignificant $(\mathrm{p}>0.05)$. Antibiotic resistances and sensitivity results were given in the Table 3.
According to antibiotic resistance and sensitivity analysis results Amikacin, Aztreonam and Rifampisin results were significantly different between patient groups $(\mathrm{p}<0.05)$.

\section{DISCUSSION}

Urinary tract infections are common among women. Among the entire population, 50\% of women suffer from urinary tract infection at least once in their lifetime and $25 \%$ tend to recur (10). In addition pregnancy increases the incidence of urinary tract infections. Physiological changes occur in kidney, ureter, bladder and renal pelvis from the eighth week of pregnancy; Bladder capacity increases, minimal dilatation of the renal pelvis occurs and ureteral peristalsis decreases with the effect of increasing progesterone. In the second and third trimester of pregnancy, secondary to the growth of the uterus, a compression effect occurs on the ureter and a physiological stasis is observed in the urinary system (11-12). This provides a basis for the development of infection. Despite the availability of multiple treatment options, urinary tract infections continue to pose a significant financial and social burden. It is extremely important to know and follow

Table 3. Antibiotic resistances and sensitivity results

\begin{tabular}{|c|c|c|c|c|c|c|c|}
\hline & \multicolumn{3}{|c|}{ Non-pregnant $(n=74 ; 46.8 \%)$} & \multicolumn{3}{|c|}{ Pregnant $(n=84 ; 53.2 \%)$} & \multirow[b]{2}{*}{$\mathbf{p}$} \\
\hline & LS & $\mathrm{S}$ & $\mathbf{R}$ & LS & S & $\mathbf{R}$ & \\
\hline Amikacin & - & $16(80.0)$ & $4(20.0)$ & $2(9.1)$ & $20(90.9)$ & - & $0.013^{\mathrm{a}}$ \\
\hline Ampicillin & - & $6(25.0)$ & $18(75.0)$ & - & $2(7.7)$ & $24(92.3)$ & $0.090^{\mathrm{a}}$ \\
\hline Ampicillin/Sulbactam & - & $11(68.8)$ & $5(31.3)$ & - & $11(55.0)$ & $9(45.0)$ & $0.400^{\mathrm{b}}$ \\
\hline Aztreonam & - & $1(50.0)$ & $1(50.0)$ & - & $2(100.0)$ & - & $<0.05$ \\
\hline Cefazolin & $1(6.7)$ & $8(53.3)$ & $6(40.0)$ & $1(5.3)$ & $12(63.2)$ & $6(31.6)$ & $0.846^{\mathrm{a}}$ \\
\hline Cefepime & $2(11.8)$ & $9(52.9)$ & $6(35.3)$ & $1(4.3)$ & $17(73.9)$ & $5(21.7)$ & $0.363^{\mathrm{a}}$ \\
\hline Cefotoxin & - & $7(87.5)$ & $1(12.5)$ & - & $5(100.0)$ & - & $0.312^{\mathrm{a}}$ \\
\hline Ceftazidime & $2(8.7)$ & $12(52.2)$ & $9(39.1)$ & - & $18(66.7)$ & $9(33.3)$ & $0.160^{\mathrm{a}}$ \\
\hline Ceftriaxone & $2(12.5)$ & $11(68.8)$ & $3(18.8)$ & - & $9(64.3)$ & $5(35.7)$ & $0.188^{\mathrm{a}}$ \\
\hline Cefuroxime & - & $13(61.9)$ & $8(38.1)$ & - & $15(60.0)$ & $10(40.0)$ & $0.895^{\mathrm{b}}$ \\
\hline Chloraphenicol & - & - & - & - & - & - & - \\
\hline Ciprofloxacin & - & $17(65.4)$ & $9(34.6)$ & - & $13(86.7)$ & $2(13.3)$ & $0.124^{\mathrm{a}}$ \\
\hline Clindamycin & - & $2(25.0)$ & $6(75.0)$ & - & $3(60.0)$ & $2(40.0)$ & $0.207^{\mathrm{a}}$ \\
\hline Colistin & - & $2(100.0)$ & - & - & $2(66.7)$ & $1(33.3)$ & $0.276^{\mathrm{a}}$ \\
\hline Erythromycin & - & $2(16.7)$ & $10(83.3)$ & - & $3(50.0)$ & $3(50.0)$ & $0.144^{\mathrm{a}}$ \\
\hline Gentamicin & $1(4.0)$ & $17(68.0)$ & $7(28.0)$ & - & $14(87.5)$ & $2(12.5)$ & $0.269^{\mathrm{a}}$ \\
\hline Imipenem & - & $23(92.0)$ & $2(8.0)$ & - & $26(100.0)$ & - & $0.087^{a}$ \\
\hline Levofloxacin & $2(8.0)$ & $22(88.0)$ & $1(4.0)$ & - & $22(84.6)$ & $4(15.4)$ & $0.096^{\mathrm{a}}$ \\
\hline Linezolid & - & $15(100.0)$ & - & - & $6(100.0)$ & - & $>0.05$ \\
\hline Meropenem & - & $22(95.7)$ & $1(4.3)$ & - & $27(100.0)$ & - & $0.209^{\mathrm{a}}$ \\
\hline Nitrofurantoin & - & $21(87.5)$ & $3(12.5)$ & - & $21(84.0)$ & $4(16.0)$ & $0.726^{a}$ \\
\hline Penicillin G & - & - & $4(100.0)$ & - & - & $4(100.0)$ & $>0.05$ \\
\hline Piperacillin Tazobactam & - & $18(78.3)$ & $5(21.7)$ & - & $25(92.6)$ & $2(7.4)$ & $0.142^{\mathrm{a}}$ \\
\hline Rifampisin & - & $3(75.0)$ & $1(25.0)$ & - & $3(100.0)$ & - & $<0.05$ \\
\hline Tetracycline & - & $4(33.3)$ & $8(66.7)$ & - & - & $6(100.0)$ & $0.051^{\mathrm{a}}$ \\
\hline Tigecycline & - & $16(100.0)$ & - & - & $8(88.9)$ & $1(11.1)$ & $0.146^{\mathrm{a}}$ \\
\hline Trimethoprim Sulfamethoxazole & - & $8(80.0)$ & $2(20.0)$ & - & $2(40.0)$ & $3(60.0)$ & $0.125^{\mathrm{a}}$ \\
\hline Vancomycin & - & $12(100.0)$ & - & - & $7(100.0)$ & - & $>0.05$ \\
\hline
\end{tabular}


the regional resistance rates to decide on the appropriate antibiotic selection. For this reason, one of the aims of this study was to determine the agent and resistance to drugs used in the treatment in the province of Mardin.

In the pregnant and non-pregnant group, E. Coli was the most common species among other microorganisms, followed by Klebsiella pneumoniae in pregnant women. The rate of Enterococcus sp. was higher in the nonpregnant group. However, none of these differences were statistically significant $(\mathrm{p}>0.05)$. Today, an increasing resistance to antibiotics among uropathogenic bacteria draws attention. In particular, the susceptibility rates of $E$. Coli strains isolated from urine cultures to combinations of oral betalactam-beta lactamase inhibitor and quinolones are gradually decreasing $(13,14)$. In their systematic study, Belete et al. (15) screened patients between 2005 and 2016 to find that $E$. Coli ranked first in urinary tract infections with a rate of $55.2 \%$, followed by Klebsiella spp. (14.6\%). Our study is in parallel with other studies. Forson et al. (16) attributed the difference in prevalence of E. Coli to genital hygiene and socioeconomic differences between communities.

Antibiotic resistance and sensitivity analysis results of amikacin, aztreonam and rifampisin were significantly different between patient groups. When considering treatment in pregnant women, these 3 drugs must be excluded. Considering socially acquired urinary tract infection, resistance to nitrofurantoin and cephalosporin groups affects empirical treatment. A need to regulate the treatment based on the antibiogram of the urine culture of the patients has emerged due to the above-mentioned resistance pattern. Some studies report that treatment change is required in one third of the patients based on the results of the urine culture and a body temperature higher than $38.5^{\circ} \mathrm{C}$ in the first trimester may have side effects on the fetus (17).

In a study conducted in Uganda, it was observed that pregnant women with a low socio-economic level, need more frequently treatment for urinary tract infections (18). The income level of people living in Mardin is low compared to other regions. Well water is still used in the villages. Hence, frequent urination, burning while urinating, and malodorous urine, which are the symptoms of general urinary tract infection, are common complaints in pregnant women in Mardin. Therefore, treatment should be given to symptomatic pregnant women. In order to be able to give empiric treatment, it is necessary to know the urinary tract infection agents of the general population and their antibiotic resistance.

In a study conducted in England, maternal age, gestational status and week, body mass index, obese women were also evaluated. There was no statistically significant association between parity and the risk of urinary tract infection (19). In our study, the average parity in the population in which this study was conducted is above three.

Brazilian Society of Infectious Diseases (SBI) and Brazilian Federation of Gynecology and Obstetrics Associations (FEBRASGO) recommend the treatment of urinary tract infection in pregnancy which was a study conducted throughout Brazil. It also draws attention to the differences in microorganisms that cause regional urinary tract infections. They state that there may be differences in development of resistance in antibiotics used regionally (20). In this study in the province of Mardin, a general evaluation was made in order to determine the regional antibiotic resistance and to guide the treatments in this region.

\section{CONCLUSION}

When choosing antibiotics in the empirical treatment of community-acquired urinary tract infections, we need to know the rates of resistance in our country and our region. To prevent the adverse obstetric consequences of urinary tract infections during pregnancy, it is important to investigate local susceptibility of microorganisms, especially common factors such as E. Coli, at certain periods. Low socio-economic level is a risk factor for urine culture contamination and further research into this topic is essential given trends in obesity worldwide. There is need to do urine culture and sensitivity from women diagnosed with in pregnancy so that appropriate antimicrobial agents are used in order to reduce the associated complications. Further work examining screening methods for the asymptomatic pregnant woman is required.

The funding organization(s) played no role in the study design; in the collection, analysis, and interpretation of data; in the writing of the report; or in the decision to submit the report for publication.

\section{ETHICAL DECLARATIONS}

Ethics Committee Approval: Ethics approval was obtained from Mardin Provincial Directorate of Health's Ethics Committee (Document no: 37201737-806.02.021332, Date: 27/08/2020).

Informed Consent: Because the study was designed retrospectively, no written informed consent form was obtained from patients.

Referee Evaluation Process: Externally peer-reviewed.

Conflict of Interest Statement: The authors have no conflicts of interest to declare.

Financial Disclosure: The authors declared that this study has received no financial support. 
Author Contributions: All of the authors declare that they have all participated in the design, execution, and analysis of the paper, and that they have approved the final version.

\section{REFERENCES}

1. Winn W Jr, Allen S, Janda W, Koneman E, Procop G, Schreckenberger P, Woods G. Koneman's color atlas and textbook of diagnostic microbiology, 6th edition. Lippincott Williams \& Wilkins, Baltimore, MD. 2006.

2. Coskun USS, Coskun G. Determination of the prevalence and antibiotic susceptibilities of extended spectrum beta-lactamase positive Escherichia coli strains 1solated from urine of outpatient patients of a state hospital. Kocatepe Tip Derg 2015; 16: 25-30.

3. Mert D, Çeken S, Ertek M; İdrar yolu enfeksiyonlarında kültürden izole edilen bakteriler ve antibiyotik duyarlılıkları.Turk Hij Den Biyol Derg 2020; 77: 25-32.

4. Forbes BA, Sahm DF, Weissfeld AS, Bailey WR. Bailey \& Scott's Diagnostic Microbiology. 12th Edition, Elsevier Mosby, St. Louis. 2007

5. Atalay CR, Ertürk NK. Gebelikte üriner sistem enfeksiyonları; Turkiye Klinikleri J Urology-Special Topics 2018; 11: 92-5.

6. Committee on Obstetric Practice. Committee Opinion No. 717: sulfonamides, nitrofurantoin, and risk of birth defects. Obstet Gynecol 2017; 130: 150-2.

7. Budak G, Budak S, Arı A, et all. Investigating the distribution of the bacteria that lead to urinary tract infections and antibiotic susceptibility of E. Coli. J Clin Anal Med 2015; 6: 216-8.

8. Johansen TE, Naber KG. Urinary Tract Infections. Antibiotics (Basel) 2014; 3: 375-7.

9. Belete MA. Bacterial Profile and ESBL Screening of Urinary Tract Infection Among Asymptomatic and Symptomatic Pregnant Women Attending Antenatal Care of Northeastern Ethiopia Region. Infect Drug Resist 2020; 13: 2579-92.

10. Marcon J, Stief CG, Magistro G. Urinary tract infections : What has been confirmed in therapy? Der Internist 2017; 58: 1242-9.

11. McCormick T, Ashe RG, Kearney PM. Urinary tract infection in pregnancy. Obstet Gynaecol 2008; 10: 156-62.

12. Glaser AP, Schaeffer AJ. Urinary tract infection and Bacteriuria in pregnancy. Urol Clin North Am 2015; 42: 547-60.

13. Kahlmeter G, Poulsen HO. Antimicrobial susceptibility of Escherichia coli from community-acquired urinary tract infections in Europe: the ECO.SENS study revisited. Int J Antimicrob Agents 2012; 39: 45-51.

14.Zhanel GG, Karlowsky JA, Harding GK, et al. A Canadian national surveillance study of urinary tract isolates from outpatients: comparison of the activities of trimethoprim-sulfamethoxazole, ampicillin, mecillinam, nitrofurantoin, and ciprofloxacin. The Canadian Urinary Isolate Study Group. Antimicrob Agents Chemother 2000; 44: 1089-92.

15. Belete MA, Saravanan M. A systematic review on drug resistant urinary tract infection among pregnant women in developing countries in Africa and Asia; 2005-2016. Infect Drug Resist 2020; 13: $1465-77$.

16. Forson AO, Tsidi WB, Nana-Adjei D, Quarchie MN, ObengNkrumah N. Correction to: Escherichia coli bacteriuria in pregnant women in Ghana: antibiotic resistance patterns and virulence factors. BMC Res Notes 2019; 12: 29.

17.Dautt-Leyva JG, Canizalez-Román A, Acosta Alfaro LF, GonzalezIbarra F, Murillo-Llanes J. Maternal and perinatal complications in pregnant women with urinary tract infection caused by Escherichia coli. J Obstet Gynaecol Res 2018; 44: 1384-90.
18. Nteziyaremye J, Iramiot SJ, Nekaka R, Musaba MW, Wandabwa J, Kisegerwa E, Kiondo P. Asymptomatic bacteriuria among pregnant women attending antenatal care at Mbale Hospital, Eastern Uganda. PLoS One. 2020; 15: e0230523.

19. O'Leary BD, Armstrong FM, Byrne S, Talento AF, O'Coigligh S. The prevalence of positive urine dipstick testing and urine culture in the asymptomatic pregnant woman: A cross-sectional study. Eur J Obstet Gynecol Reprod Biol 2020; 253: 103-7. doi:10.1016/j. ejogrb.2020.08.004

20.de Rossi P, Cimerman S, Truzzi JC, et al. Joint report of SBI (Brazilian Society of Infectious Diseases), FEBRASGO (Brazilian Federation of Gynecology and Obstetrics Associations), SBU (Brazilian Society of Urology) and SBPC/ML (Brazilian Society of Clinical Pathology/Laboratory Medicine): recommendations for the clinical management of lower urinary tract infections in pregnant and non-pregnant women. Braz J Infect Dis 2020; 24 110-9. doi:10.1016/j.bjid.2020.04.002 